\title{
DIFERENCIAL DE SALÁRIOS NOS MUNICÍPIOS DO ESTADO DO CEARÁ: UMA APLICAÇÃO DA DECOMPOSIÇÃO DE OAXACA*
}

\author{
Paulo Araújo Pontes ${ }^{*}$
}

\begin{abstract}
RESUMO Políticas de desenvolvimento econômico são adotadas nas mais diferentes regiões. No caso do Ceará, optou-se, de forma inquestionável, por políticas industriais para se chegar a esse fim, sendo a atração de investimentos um instrumento amplamente utilizado, inclusive para promover o desenvolvimento dos municípios fora da região mais evoluída do Estado. Dessa forma, o objetivo deste artigo é verificar se essa política está afetando o mercado de trabalho nos municípios cearenses fora da região metropolitana de Fortaleza. Neste intuito, foi utilizada a decomposição de Oaxaca para mensurar o diferencial de salários entre os municípios. Como resultado, observa-se a existência de considerável diferencial de retribuição salarial em decorrência da implantação de unidades fabris em alguns municípios do Estado do Ceará.
\end{abstract}

Palavras-chave: política industrial; atração de investimentos; economia do Ceará

Código JEL: $\mathrm{R}_{5} 8$ - Regional Development Policy

WAGE INEQUALITY IN MUNICIPALITIES OF CEARÁ:

AN APPLICATION OF OAXACA DECOMPOSITION

ABSTRACT Economic development policies are adopted everywhere in the World. In the case of Ceara, the option made was to elect, unquestionably, an industrial policy in order to achieve higher levels of economic development. In this context, the attraction of productive investments is an instrument that is often used. Ano-

\footnotetext{
* Artigo enviado em 15 de maio de 2006 e aprovado em 15 de agosto de 2007.

** Analista de Políticas Públicas do Instituto de Pesquisa e Estratégia Econômica do Ceará (IPECE), e-mail: pauloarpo@click21.com.br
} 
ther feature of such a policy is that it also aims to improve economic conditions in municipalities that are not part of the most developed region in the State. In this way, this article verify if this politics is affecting the work market in the municipalities of the Ceará. In this intention, the decomposition of Oaxaca was used to mesure the differential of wages between the municipalities. As a result of such endeavours, however, it is possible to observe a considerable dispersion in wages among municipalities in Ceara, specially if the ones receiving new factories are compared to the others.

Key words: industrial policy; attraction of investiments; Ceará economic 


\section{INTRODUÇÃO}

A preocupação com o desenvolvimento do Estado do Ceará é uma constante desde meados do século XX, haja vista que diversos Governos estaduais elaboraram e implementaram políticas públicas com esse intuito. Deve-se destacar o fato de que, para alcançar esse objetivo, foi atribuído relevante papel ao setor industrial.

Com relação às políticas de incentivo à industrialização do Estado, é possível identificar dois momentos distintos. No primeiro, que compreende as décadas de 1960 e 1970, observa-se que houve acentuada preocupação com o desenvolvimento da infra-estrutura. ${ }^{1}$ No segundo, com origem na década de 1980, a preocupação principal foi a atração de investimentos industriais para o Ceará, ${ }^{2}$ e o principal marco dessa linha de atividade foi a instituição, em 1979, do FDI (Fundo de Desenvolvimento Industrial).

Desde então, os recursos do FDI são utilizados em diversos programas, entre os quais se pode destacar o Provin (Programa de Atração de Investimentos Industriais), o qual concede incentivos fiscais para empresas industriais que se instalam no Ceará. O principal benefício disponibilizado por esse Programa é um empréstimo calculado sobre o valor do ICMS (Imposto sobre Circulação de Mercadorias e Serviços) a ser recolhido pelas empresas beneficiadas.

Supõe-se que as empresas industriais atraídas venham a contratar mãode-obra local e, por conseqüência, aumentar a renda nos municípios onde estas estejam instaladas. Assim, um importante resultado dessa política é o maior rendimento das pessoas ocupadas nos municípios-sedes de empresas atraídas.

Nesse sentido, o Governo do Estado concluiu que a instalação de empresas industriais nos municípios fora da RMF (Região Metropolitana de Fortaleza) poderia alavancar o desenvolvimento destes, deixando-os menos sujeitos aos efeitos das épocas de estiagem. Assim, foram ampliados os incentivos concedidos às empresas que implantassem plantas produtivas além da RMF.

É de se esperar, portanto, que venha a surgir um diferencial de salários entre os municípios onde foram instaladas empresas incentivadas e naqueles que não são sedes desse tipo de empreendimento. Assim, o objetivo deste trabalho é investigar se existe esse diferencial. 
Este artigo está organizado em cinco tópicos, contando com esta introdução. O segundo apresenta, resumidamente, a política de atração de investimentos do Estado do Ceará e alguns resultados. No terceiro módulo, são descritos o tratamento dado à base de dados e algumas estatísticas descritivas dessa base. No quarto, são exibidos o modelo econométrico e os resultados por este obtido, enquanto no quinto e último segmento estão as conclusões deste ensaio.

\section{O FDI: FUNDO DE DESENVOLVIMENTO INDUSTRIAL}

O FDI foi criado em 1979, em lei sancionada pelo governador Virgílio Távora (Lei $\left.n^{\circ} 10.367\right)$, dotando o Estado do Ceará de um instrumento legal para a concessão de incentivos às empresas industriais que investissem no Estado.

As principais formas de incentivo previstas pela referida legislação eram a concessão de empréstimos de médio e longo prazos, aquisição de ações, debêntures ou outros títulos emitidos por empresas industriais e subsídio de encargos financeiros para empresas com sede no Ceará.

Paralelamente foram criados, desde a década de 1980, programas que utilizariam os recursos disponibilizados por esse Fundo, destacando-se o Programa de Atração de Investimentos de Empresas Industriais (Provin), que teve origem ainda no início da década de 1980.

Em 1989, o Provin foi reformulado e passou a conceder, como principal forma de incentivo, um empréstimo sobre o ICMS arrecadado pelas empresas incentivadas. ${ }^{3}$ Esses recursos deveriam ser pagos no prazo de 36 meses e eram corrigidos pela metade do IPC. A duração desse incentivo era de 72 meses.

Nova reformulação dos incentivos foi implementada em 1993, sendo a principal mudança observada a ampliação dos incentivos para empresas localizadas além da RMF. ${ }^{4}$

Em 1995 registrou-se outra reformulação, quando se adotou a lógica dos raios econômicos, ou seja, quanto mais distante da RMF fosse instalada a empresa industrial, maiores seriam os incentivos, conforme está descrito no quadro 1. Essa nova formulação foi motivada pela preocupação de alavancar o desenvolvimento dos municípios fora da RMF. 
Quadro 1: Alterações FDI-PROVIN - 1995

\begin{tabular}{|c|c|c|c|c|c|}
\hline $\begin{array}{l}\text { Distância } \\
\text { quanto à RMF }\end{array}$ & Fin. do ICMS & $\begin{array}{l}\text { Prazo } \\
\text { (meses) }\end{array}$ & $\begin{array}{l}\text { Carência } \\
\text { (meses) }\end{array}$ & Retorno & $\begin{array}{c}\text { Correção } \\
\text { e juros }\end{array}$ \\
\hline Na RMF & $60 \%$ & 72 & 36 & $60 \%$ & $100 \%$ IGPM \\
\hline Até $300 \mathrm{~km}$ da RMF & $75 \%$ & 120 & 36 & $25 \%$ & $100 \%$ IGPM \\
\hline Entre $300 \mathrm{~km}$ e $500 \mathrm{~km}$ da RMF & $75 \%$ & 156 & 36 & $25 \%$ & $100 \%$ IGPM \\
\hline Superior a 500 km da RMF & $75 \%$ & 180 & 36 & $25 \%$ & $100 \%$ IGPM \\
\hline
\end{tabular}

Em 2002, esses incentivos foram alterados mais uma vez, ocasião em que se buscava incentivar a localização de empresas em determinados municípios, notadamente naqueles que possuíam algum germe de aglomeração industrial (Pontes, 2003). A quinta e última reformulação ocorreu em maio de 2003, e desse momento em diante foi adotado um sistema de pontos em que os incentivos cresceriam à medida que a empresa atendesse a algumas prioridades estabelecidas pelo Governo do Estado (para detalhes, ver Pontes, Viana, 2005).

Dentre as diversas reformulações, observa-se, do que foi exposto há pouco, que a alteração de 1995 foi a de maior longevidade. Além disso, deve-se frisar, como se destacou (Pontes, 2003), que a atração de investimentos se intensificou após 1995.

Como resultado dessa intervenção do Governo do Estado, foram atraídas, entre janeiro de 1995 e janeiro de 2003, 385 empresas, que previam investimentos, a preços de dezembro de 2002, de 7,05 bilhões de reais, segundo dados da SDE (Secretária de Desenvolvimento Econômico). As empresas atraídas previam, ainda, a abertura de cerca de 77 mil postos de trabalho. Desses investimentos, 1,1 bilhão de reais, 36,55 mil empregos previstos e 163 empresas deveriam se localizar fora da RMF. Destaque-se o fato de que essa concentração de investimentos e empresas atraídas já havia sido identificada em Almeida \& Silva (2000).

\subsection{Breves notas sobre os custos e benefícios da adoção de uma política de atração de investimentos industriais}

Como exposto anteriormente, o FDI tem como principal mecanismo de incentivo a isenção de parte do ICMS $^{5}$ a ser recolhido pelas empresas industriais beneficiadas. Nesse sentido, pode-se alegar que esse tipo de política poderá ter impactos fiscais negativos para o Estado. 
Os defensores desse tipo de política, no entanto, argumentam que, em razão de a empresa ser nova no Estado, ela não arrecadava ICMS. Dessa forma, o incentivo fiscal é concedido sobre o incremento da arrecadação originada pela nova empresa, não causando, portanto, impactos na receita fiscal do Estado.

Outro caso que merece atenção é quando a empresa é do próprio Estado e pleiteia o benefício. Nessa hipótese, haverá o impacto fiscal negativo referido há instantes. ${ }^{6}$ Para evitar esse problema, é necessário estabelecer critérios à concessão do benefício, bem como procedimentos de fiscalização para as empresas beneficiadas, a fim de evitar, ou ao menos minimizar, a ocorrência dessa prática.

Por outro lado, espera-se que as empresas atraídas provoquem externalidades positivas, como as previstas por Marshall (1982) e Krugman (1997), nos municípios onde se instalarem; isto é, que o emprego e o fluxo de negócios ensejados pela instalação de uma firma industrial redundem em crescimento da renda e, concomitantemente, da economia local.

Esses são alguns dos argumentos utilizados pelos defensores e críticos de políticas de atração de investimentos industriais via incentivos fiscais, como é o caso do FDI. Não se pretende, aqui, no entanto, abordar todos os argumentos utilizados, mas apenas deixar claro que ainda não existe consenso nesse tipo de política.

\section{DESCRIÇÃO DA BASE DE DADOS}

Na seção anterior, foi introduzido o principal mecanismo de política industrial do Estado do Ceará, que são os incentivos previstos pelo sistema FDIProvin. Comentou-se, ainda, que o principal intuito do FDI é a promoção do desenvolvimento do Estado, com notado cuidado relativo à "interiorização" das empresas atraídas por esse sistema de incentivos.

Espera-se que nos municípios onde for instalada alguma empresa incentivada ocorra um crescimento no número de pessoas empregadas, ou seja, acredita-se que a organização beneficiada contrate a mão-de-obra local para a produção. Dessa forma, é razoável supor que haverá incremento na renda do município. Portanto, um relevante efeito da política de atração de investimentos é o crescimento da renda da população nos municípios onde se instalaram empresas industriais incentivadas. 
Identifica-se, com efeito, a possibilidade de avaliar essa política de incentivo à industrialização pelo incremento da renda da população. Nesse sentido, duas fontes de dados podem ser utilizadas, a primeira das quais são os registros da Rais-Caged, organizados pelo Ministério do Trabalho, e a segunda os microdados do Censo de $2000,{ }^{7}$ realizado pelo IBGE.

Os indicadores do Ministério do Trabalho referem-se apenas ao mercado formal, enquanto aqueles coletados pelo IBGE compreendem também o mercado informal. Dadas as externalidades que uma empresa pode ocasionar em determinada região, pode-se supor que os trabalhadores do setor informal poderão ser beneficiados pelo fato de morarem em um município que possua uma empresa incentivada pelo sistema FDI-Provin. Assim, optou-se pelo censo de 2000. Deve-se, no entanto, frisar que a escolha do Censo restringe a análise a ser realizada ao período de 1995 a 2000.

Escolhida a base de dados a ser utilizada, foram aplicados alguns filtros, sendo o primeiro referente à população ocupada na semana de referência. Em seguida, foram selecionadas apenas as pessoas empregadas com e sem carteira assinada, os trabalhadores por conta própria e os empregadores. Com essas restrições, chegou-se ao universo de 986.769 pessoas ocupadas fora da RMF, em julho de $2000 .{ }^{8}$ Posteriormente, as pessoas foram classificadas pelos grandes setores em que trabalhavam (agricultura, indústria e serviços).

Paralelamente, foram identificados os municípios que receberam empresas beneficiadas pelos incentivos estaduais no período de janeiro de 1995 a dezembro de 1999. A relação desses municípios pode ser encontrada no anexo 1 deste trabalho. ${ }^{9}$

Após a identificação dos municípios que possuem ao menos uma empresa incentivada, foi possível obter as primeiras estatísticas descritivas, apresentadas a seguir. O primeiro fato que chama a atenção, e pode ser verificado na tabela 1, é que os municípios não possuidores de empresas incentivadas têm parcela significativa de sua população ocupada no setor agrícola.

Deve-se observar, ainda na tabela 1, que a maior parte da população ocupada no setor agrícola se encontra nos municípios que não possuem empresas incentivadas. Já nos municípios onde há empresas incentivadas, a maior parte da população ocupada encontra-se, nesta ordem, no setor de serviços e na indústria. 
Anexo 1: Relação dos municípios-sedes de empresas incentivadas pelo FDI-Provin

\begin{tabular}{llll}
\hline Abaiara & Cedro & Itarema & Pindoretama \\
\hline Aquiraz & Chorozinho & Jaguaribe & Quixeramobim \\
\hline Aracati & Crateús & Jaguaruana & Russas \\
\hline Barbalha & Crato & Juazeiro do Norte & S. G. do Amarante \\
\hline Barreira & Eusébio & Limoeiro do Norte & Santana do Acaraú \\
\hline Baturité & Forquilha & Maracanaú & Sobral \\
\hline Beberibe & Fortaleza & Maranguape & Santa Quitéria \\
\hline Boa Viagem & Guaramiranga & Milhã & Tianguá \\
\hline Brejo Santo & Guaiúba & Morada Nova & Trairi \\
\hline Camocim & Horizonte & Nova Olinda & Ubajara \\
\hline Canindé & Icapuí & Nova Russas & Uruburetama \\
\hline Caridade & Iguatu & Pacajus & \\
\hline Cariús & Itaitinga & Pacatuba & \\
\hline Cascavel & Itapajé & Paracuru & \\
\hline Caucaia & Itapipoca & Pentecoste & \\
\hline
\end{tabular}

Tabela 1: População ocupada por setor nos municípios do Ceará (exclusive a RMF) - 2000

\begin{tabular}{lcccccr}
\hline \multirow{2}{*}{ Setores } & \multicolumn{2}{c}{ Sem empresa incentivada } & \multicolumn{2}{c}{$\begin{array}{c}\text { Ao menos uma } \\
\text { empresa incentivada }\end{array}$} & \multicolumn{2}{c}{ Total } \\
\cline { 2 - 7 } & Qt & $\%$ & Qt & $\%$ & Qt & $\%$ \\
\hline Agricultura & 175.762 & 35,72 & 115.304 & 23,31 & 291.066 & 29,50 \\
\hline Indústria & 85.182 & 17,31 & 121.522 & 24,56 & 206.704 & 20,95 \\
\hline Serviço & 231.097 & 46,97 & 257.902 & 52,13 & 488.999 & 49,56 \\
\hline Total & 492.041 & 100,00 & 494.728 & 100,00 & 986.769 & 100,00 \\
\hline Fonte: Censo, 2000. & & & & & &
\end{tabular}

Com relação à média salarial, é possível observar, pela tabela 2, que o salário médio dos municípios com ao menos uma empresa incentivada é superior àquele verificado nos municípios que não possuem esse tipo de empresa. É interessante ressaltar que esse fato se repete em todos os setores de atividade.

No tocante ao salário mediano, ainda na tabela 2, é possível verificar que este também é superior, em todos os setores, nos municípios que possuem empresas incentivadas.

No que diz respeito ao vínculo trabalhista, vê-se, na tabela 3, que os municípios com empresas incentivadas possuem $21,8 \%$ das pessoas ocupadas com carteira assinada, ao passo que, naqueles sem empresas incentivadas, apenas $12,6 \%$ das pessoas ocupadas possuem esse vínculo. 
Tanto nos municípios com empresas incentivadas como nos que não as possuem, pode-se constatar elevada participação da população ocupada, que se encontra empregada sem carteira assinada. Deve-se notar, no entanto, que, nos municípios sem empresas incentivadas, esse quadro é mais grave.

Dado que o trabalhador com carteira assinada tem direito aos serviços de seguridade social, é válido assinalar que, nos municípios com empresas incentivadas, a população ocupada encontra melhores condições de ocupação do que naqueles que não as possuem.

Relativamente à melhor qualidade das condições de ocupação dos trabalhadores nos municípios com empresas incentivadas, é possível verificar, pela tabela 4, que estes trabalham três horas por semana a mais do que aqueles que moram em municípios não possuidores desse tipo de empresa. Esse fato é observado em todos os setores econômicos.

Tabela 2: Salário médio e mediano dos setores econômicos nos municípios do Ceará (exclusive a RMF), Ceará 2000 (preços correntes)

\begin{tabular}{lcccccc}
\hline & \multicolumn{3}{c}{ Média } & & \multicolumn{2}{c}{ Mediana } \\
\hline Setores & $\begin{array}{c}\text { Municípios } \\
\text { sem empresa } \\
\text { incentivada }\end{array}$ & $\begin{array}{c}\text { Município } \\
\text { com ao menos } \\
\text { uma empresa }\end{array}$ & Total & $\begin{array}{c}\text { Municípios } \\
\text { sem empresa } \\
\text { incentivada }\end{array}$ & $\begin{array}{c}\text { Município } \\
\text { com ao menos } \\
\text { uma empresa } \\
\text { incentivada }\end{array}$ & Total \\
\hline Agricultura & 130,72 & 149,71 & 138,24 & 80 & 100 & 100 \\
\hline Indústria & 178,69 & 242,34 & 216,11 & 130 & 151 & 151 \\
\hline Serviço & 300,99 & 386,75 & 346,22 & 151 & 162 & 151 \\
\hline Total & 218,99 & 296,03 & 257,62 & 120 & 151 & 150 \\
\hline Fonte: Censo, 2000. & & & & & 150
\end{tabular}

Fonte: Censo, 2000.

Tabela 3: Vínculo empregatício da população ocupada, Ceará 2000

\begin{tabular}{lcccccc}
\hline \multirow{2}{*}{ Condição } & \multicolumn{2}{c}{$\begin{array}{c}\text { Municípios sem } \\
\text { empresa incentivada }\end{array}$} & \multicolumn{2}{c}{$\begin{array}{c}\text { Município com ao menos } \\
\text { uma empresa incentivada }\end{array}$} & \multicolumn{2}{c}{ Total } \\
\cline { 2 - 8 } & Qt & $\%$ & Qt & $\%$ & Qt & $\%$ \\
\hline Empregado d/ carteira & 62.256 & 12,65 & 108.065 & 21,84 & 170.321 & 17,26 \\
\hline Empregado s/ carteira & 213.689 & 43,43 & 201.613 & 40,75 & 415.302 & 42,09 \\
\hline Empregador & 8.304 & 1,69 & 11.680 & 2,36 & 19.984 & 2,03 \\
\hline Conta própria & 207.792 & 42,23 & 173.370 & 35,04 & 381.162 & 38,63 \\
\hline Total & 492.041 & 100,00 & 494.728 & 100,00 & 986.769 & 100,00 \\
\hline
\end{tabular}

Fonte: Censo, 2000. 
Ressalte-se, ainda, que a população ocupada dos municípios com ao menos uma empresa incentivada possui melhor nível educacional, como pode ser observado no gráfico 1 , do que nos municípios que não possuem empresas incentivadas. Verifica-se no referido gráfico que um percentual superior a $25 \%$ da população ocupada dos municípios sem empresas incentivadas tem menos de um ano de instrução. Já os municípios com ao menos uma empresa incentivada apresentam quase $20 \%$ de sua população ocupada com 11 ou mais anos de estudos.

Com esses indicadores, é possível constatar que a população ocupada dos municípios com empresas incentivadas apresenta melhor salário médio, possui melhores condições de trabalho (dado o maior percentual de pessoas com carteira assinada) e melhor escolarização do que a população dos municípios sem empresa incentivada.

Tabela 4: Horas trabalhadas por semana no trabalho principal, Ceará (exclusive a RMF) 2000

\begin{tabular}{lccc}
\hline Setores & $\begin{array}{c}\text { Municípios sem } \\
\text { empresa incentivada }\end{array}$ & $\begin{array}{c}\text { Município com ao menos } \\
\text { uma empresa incentivada }\end{array}$ & Total \\
\hline Agricultura & 40,45 & 42,66 & 41,33 \\
\hline Indústria & 42,55 & 44,18 & 43,51 \\
\hline Serviço & 39,15 & 42,81 & 41,08 \\
\hline Total & 40,21 & 43,11 & 41,66 \\
\hline
\end{tabular}

Fonte: Censo, 2000.

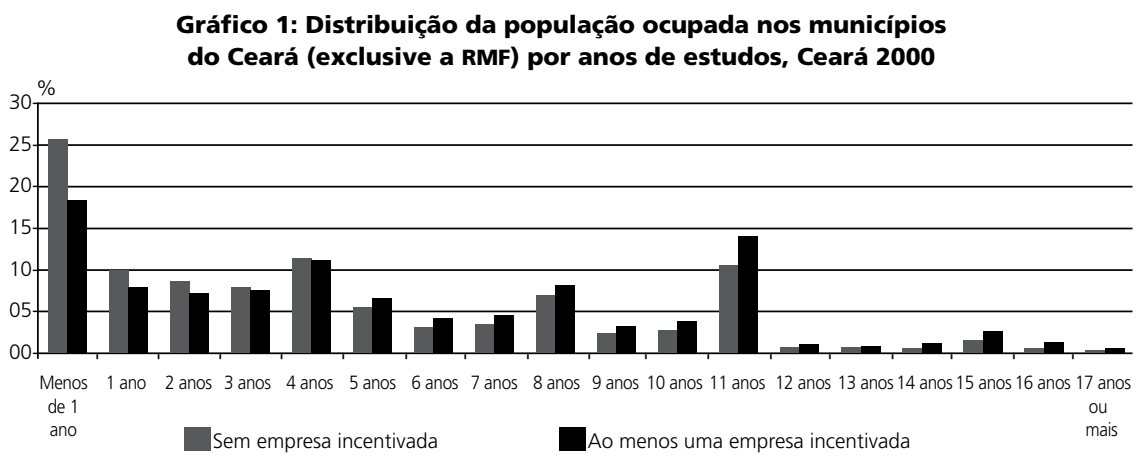




\section{MODELO E RESULTADOS EMPÍRICOS}

\subsection{0 modelo}

No tópico anterior, foi observado que a população ocupada nos municípios que possuem ao menos uma empresa incentivada apresentam melhor salário médio do que a dos municípios sem empresa incentivada.

Cumpre ainda averiguar o quanto da diferença salarial entre os municípios pode ser atribuído ao fato de o município possuir ou não empresas incentivadas. Para essa tarefa, optou-se por utilizar a decomposição de Oaxaca (1973), descrita a seguir.

A decomposição de Oaxaca (1973) é um método utilizado para mensurar o efeito da discriminação e de políticas públicas, e consiste, basicamente, em comparar dois grupos de indivíduos, um desses pertencente a determinada categoria e o outro, não. Nesse método, no primeiro momento, são estimadas duas equações de salários para cada um dos grupos ora descritos. Aqui, os indivíduos foram separados entre aqueles que moram em municípios com empresas incentivadas e os que residem em municípios sem esse tipo de organização. As equações são as seguintes:

$$
\begin{aligned}
& \operatorname{Ln}\left(Y_{1}\right)=\beta_{0}+\beta_{1} \text { indivíduos }_{1}+\beta_{2} \text { setor }_{1}+\beta_{3} \text { vinculo }_{1}+e_{1} \\
& \operatorname{Ln}\left(Y_{2}\right)=\alpha_{0}+\alpha_{1} \text { indivíduos }_{2}+\alpha_{2} \text { setor }_{2}+\alpha_{3} \text { vinculo }_{2}+e_{2}
\end{aligned}
$$

em que:

$Y_{i}=$ salário/hora da pessoa.

Indivíduos $_{\mathrm{i}}=$ vetor de variáveis com as características dos indivíduos, tais como raça (branco $=1$ ou não-branco $=0)$, sexo $($ homem $=1)$, idade, idade ao quadrado e anos de educação.

Esse conjunto de variáveis busca explicar como as características individuais influem no prêmio salarial. Nesse caso, as variáveis idade e idade ao quadrado são uma proxy de experiência profissional; já anos de estudo mensuram a influência de um ano a mais de estudo no salário, e as outras duas indicam a diferenciação de salários que ocorre contra pessoas do sexo feminino e/ou da raça negra. 
Setor ${ }_{\mathrm{i}}=$ vetor de variáveis dummies que indicam o setor em que o indivíduo exerce o trabalho principal ${ }^{10}$ (agricultura, indústria de transformação, serviços industriais, construção civil, extrativa mineral, administração pública, comércio e outros serviços). Essas variáveis foram incluídas no modelo, pois supõe-se que o prêmio salarial também é afetado pelo setor em que o indivíduo exerce sua atividade principal.

Vinculo $_{\mathrm{i}}=$ vetor de variáveis dummies que indicam o vínculo que o trabalhador possui com a empresa ${ }^{11}$ (carteira assinada, sem carteira, empregador e conta própria).

$\mathrm{e}_{\mathrm{i}}=$ erro aleatório com distribuição normal, média zero e distribuído de forma independente.

O subscrito " $i$ " indica as pessoas que moram em municípios com empresas incentivadas (1) ou não (2).

Deve-se ressaltar, ainda, que se espera obter coeficientes positivos para as variáveis anos de estudo e idade, pois acredita-se que quanto maiores a escolaridade e a experiência do indivíduo maior o salário por ele recebido. Já para as variáveis branco e sexo é esperado sinal positivo.

Em seguida, a primeira equação é subtraída da segunda e aplica-se o operador esperança, obtendo-se a diferença dos prêmios salariais:

$$
\begin{aligned}
& E\left(Y_{1}-Y_{2}\right)=E\left(\beta_{0}+\beta_{1} \text { ind }_{1}+\beta_{2} \text { setor }_{1}+\beta_{3} \text { vinculo }_{1}-\alpha_{0}-\right. \\
& \left.-\alpha_{1} \text { ind }_{2}-\alpha_{2} \text { setor }_{2}+\alpha_{3} \text { vinculo }_{2}\right)
\end{aligned}
$$

Dado que a esperança do erro aleatório é igual a zero, ele desaparece na equação 2 . O passo seguinte é subtrair e somar $\beta_{1}$ ind $_{2}, \beta_{2}$ setor $_{2}$ e $\beta_{3}$ vinculo $_{2}$, obtendo-se a seguinte expressão:

$$
\begin{aligned}
& E\left(\left(Y_{1}-Y_{2}\right)=E\left(\left(\beta_{0}-\alpha_{0}\right)+\beta_{1}\left(\text { ind }_{1}-\text { ind }_{2}\right)+\beta_{2}\left(\text { setor }_{1}-\text { setor }_{2}\right)+\right.\right. \\
& +\beta_{3}\left(\text { vinculo }_{1}-\text { vinculo }_{2}\right)+\left(\beta_{1}-\alpha_{1}\right) \text { ind }_{2}+\left(\beta_{2}-\alpha_{2}\right) \text { setor }_{2}+ \\
& \left.+\left(\beta_{3}-\alpha_{3}\right) \text { vinculo }_{2}\right)
\end{aligned}
$$

Os quatro primeiros termos do lado direito dessa expressão explicam a diferença de salários, dada a diversidade das características dos indivíduos. Já os três últimos termos explicam a diferença em virtude do efeito de a pessoa residir em um município com empresas incentivadas. 
Se a equação 3 for dividida por $\mathrm{E}\left(Y_{1}-Y_{2}\right)$ e multiplicada por 100, é possível calcular a contribuição percentual da diferença salarial explicada pelas diferenças individuais e pelo fato de a pessoa morar em município com empresa incentivada. Obtém-se, assim, a equação 4.

$$
\begin{aligned}
& 100=\frac{E\left(\left(\beta_{0}-\alpha_{0}\right)+\beta_{1}\left(\text { ind }_{1}-\text { ind }_{2}\right)+\beta_{2}\left(\text { setor }_{1}-\text { setor }_{2}\right)+\right.}{E\left(Y_{1}-Y_{2}\right)} \\
& \frac{\left.+\beta_{3}\left(\text { vinculo }_{1}-\text { vinculo }_{2}\right)\right)}{E\left(Y_{1}-Y_{2}\right)} \times 100+\frac{E\left(\left(\beta_{1}-\alpha_{1}\right) \text { ind }_{2}+\left(\beta_{2}-\alpha_{2}\right) \text { setor }_{2}\right.}{E\left(Y_{1}-Y_{2}\right)}+ \\
& \frac{\left.+\left(\beta_{3}-\alpha_{3}\right) \text { vinculo }_{2}\right)}{E\left(Y_{1}-Y_{2}\right)} \times 100
\end{aligned}
$$

A equação 4 pode ser, assim, desmembrada em duas partes:

$$
\begin{aligned}
& \frac{\text { Dif. \% dascaracteristicas }=E\left(\left(\beta_{0}-\alpha_{0}\right)+\beta_{1}\left(\text { ind }_{1}-\text { ind }_{2}\right)+\right.}{E\left(Y_{1}-Y_{2}\right)} \\
& \frac{\left.+\beta_{2}\left(\text { setor }_{1}-\text { setor }_{2}\right)+\beta_{3}\left(\text { vinculo }_{1}-\text { vinculo }_{2}\right)\right)}{E\left(Y_{1}-Y_{2}\right)} \times 100
\end{aligned}
$$

Dif. \% decorrentedapolítica $=E\left(\left(\beta_{1}-\alpha_{1}\right)\right.$ ind $_{2}+$ $E\left(Y_{1}-Y_{2}\right)$

$\frac{\left.+\left(\beta_{2}-\alpha_{2}\right) \text { setor }_{2}+\left(\beta_{3}-\alpha_{3}\right) \text { vinculo }_{2}\right)}{E\left(Y_{1}-Y_{2}\right)} \times 100$

Para o cálculo da equação 4, utilizam-se as médias das variáveis explicativas, ora listadas, tanto para municípios com empresas incentivadas quanto para aqueles que não as possuem. Em seguida, deve-se calcular o prêmio salarial médio para as duas situações e computar a diferença entre ambos. O último passo consiste no cálculo das duas partes da equação 4. Os resultados obtidos são apresentados na seqüência. 
Tabela 5: Resultado da regressão para os municípios com e sem empresas incentivadas

\begin{tabular}{|c|c|c|c|c|c|c|}
\hline \multirow[t]{2}{*}{ Variáveis } & \multicolumn{3}{|c|}{$\begin{array}{l}\text { Município com ao menos } \\
\text { uma empresa incentivada }\end{array}$} & \multicolumn{3}{|c|}{$\begin{array}{c}\text { Municípios sem } \\
\text { empresa incentivada }\end{array}$} \\
\hline & Coeficiente & $\mathrm{T}$ & $P>|t|$ & Coeficiente & $\mathrm{T}$ & $\mathrm{P}>|\mathrm{t}|$ \\
\hline Sexo & 0,372 & 41,89 & 0 & 0,375 & 41,4 & 0 \\
\hline Idade & 0,059 & 37,36 & 0 & 0,046 & 33,26 & 0 \\
\hline Idade ao quadrado & $-0,001$ & $-26,38$ & 0 & 0,000 & $-22,49$ & 0 \\
\hline Educação & 0,104 & 98,43 & 0 & 0,099 & 93,18 & 0 \\
\hline Indústria de transformação & 0,158 & 13,01 & 0 & 0,007 & 0,56 & 0,575 \\
\hline Serviços industriais & 0,589 & 14,81 & 0 & 0,414 & 8,77 & 0 \\
\hline Construção civil & 0,389 & 28,77 & 0 & 0,355 & 28,1 & 0 \\
\hline Extrativa mineral & 0,337 & 6,92 & 0 & 0,176 & 3,92 & 0 \\
\hline Administração pública & 0,577 & 32,41 & 0 & 0,569 & 39,86 & 0 \\
\hline Comércio & 0,333 & 27,65 & 0 & 0,361 & 29,38 & 0 \\
\hline Outros serviços & 0,407 & 34,65 & 0 & 0,478 & 43,98 & 0 \\
\hline Branco & 0,102 & 13,54 & 0 & 0,101 & 14,39 & 0 \\
\hline Carteira assinada & 0,161 & 16,14 & 0 & 0,292 & 27,83 & 0 \\
\hline Sem carteira & $-0,054$ & $-5,95$ & 0 & $-0,001$ & $-0,14$ & 0,888 \\
\hline Empregador & 0,987 & 30,01 & 0 & 0,994 & 27,77 & 0 \\
\hline Constante & $-1,087$ & $-33,78$ & 0 & $-0,946$ & $-32,08$ & 0 \\
\hline Observações & & & 53.069 & & & 65.990 \\
\hline $\mathrm{F}$ & & & $1.814,68$ & & & $2.043,68$ \\
\hline Prob F & & & 0 & & & 0 \\
\hline $\mathrm{R}^{2}$ & & & 0,3607 & & & 0,308 \\
\hline
\end{tabular}

Fonte: Amostra do Censo, 2000. Elaboração própria.

\subsection{Resultados empíricos}

$\mathrm{Na}$ tabela 5 são apresentados os resultados estimados para as equações de salário dos municípios com e sem empresas incentivadas. ${ }^{12}$ Relativamente aos municípios com empresa incentivada, pode-se observar que todas as variáveis utilizadas apresentam valores significativos.

Já no grupo dos municípios sem empresas incentivadas, é possível verificar que as variáveis indústria de transformação e empregado sem carteira apresentam valores pouco significativos, ou seja, rejeita-se a hipótese de que o coeficiente dessas variáveis seja diferente de zero. Esse fato leva a crer que, nos municípios sem empresas incentivadas, a indústria de transformação paga um salário/hora próximo àquele verificado no setor agrícola (grupo de comparação), e os trabalhadores sem carteira possuem remuneração similar àquela recebida pelos trabalhadores por conta própria. Deve-se ainda frisar que o teste $\mathrm{F}$ foi significativo para ambas as regressões. 
O passo seguinte à estimação foi calcular as médias das variáveis utilizadas e estimar o salário médio das pessoas que moram em municípios com empresas incentivadas e sem empresas incentivadas. Essas médias são apresentadas na tabela 6. Destaque-se o fato de que, no caso das variáveis dummies, a média corresponde à proporção de pessoas que possuem a característica. Assim, observa-se, por exemplo, que, nos municípios com empresa incentivada, $69,6 \%$ das pessoas ocupadas são homens, enquanto nos municípios sem empresas incentivadas estes correspondem a $71,1 \%$ da população ocupada.

Observa-se, ainda na tabela 6, que, nos municípios com empresas, incentivadas, a população ocupada possui, em média, um ano a mais de educação do que nos municípios sem essas empresas. Outra importante observação é a diferença de 0,356 entre o logaritmo do salário/hora entre as duas categorias em análise, a qual equivale a $\mathrm{R} \$ 1,43$ a mais, por hora trabalhada, para os indivíduos que moram em município com empresas incentivadas.

A última etapa da decomposição de Oaxaca é aquela preconizada pela equação 4, ou seja, estimar o quanto da diferença salarial decorre das dife-

Tabela 6: Média das variáveis explicativas

\begin{tabular}{lcc}
\hline Variável & $\begin{array}{c}\text { Município com ao menos } \\
\text { uma empresa incentivada }\end{array}$ & $\begin{array}{c}\text { Municípios sem } \\
\text { empresa incentivada }\end{array}$ \\
\hline Sexo & 0,696 & 0,711 \\
\hline Idade & 35,185 & 36,342 \\
\hline Idade ao quadrado & $1.409,594$ & $1.505,576$ \\
\hline Educação & 5,143 & 4,086 \\
\hline Indústria de transformação & 0,158 & 0,096 \\
\hline Serviços industriais & 0,004 & 0,004 \\
\hline Construção civil & 0,076 & 0,069 \\
\hline Extrativa mineral & 0,004 & 0,004 \\
\hline Administração pública & 0,053 & 0,072 \\
\hline Comércio & 0,187 & 0,134 \\
\hline Outros serviços & 0,270 & 0,255 \\
\hline Branco & 0,370 & 0,364 \\
\hline Carteira assinada & 0,213 & 0,124 \\
\hline Sem carteira & 0,412 & 0,433 \\
\hline Empregador & 0,023 & 0,016 \\
\hline Log (salário/hora)* & 2,446 & 2,090 \\
\hline Eonte:Amostra do Censo & &
\end{tabular}

Fonte: Amostra do Censo, 2000. Elaboração própria.

*Estimado. 
Tabela 7: Influência na diferença do logaritmo do salário/hora

\begin{tabular}{lcc}
\hline Descrição & $\begin{array}{c}\text { Efeito no logaritmo } \\
\text { do salário/hora }\end{array}$ & \% explicado \\
\hline Diferença de salários & 0,356 & 38,345 \\
\hline Dif. decorrente das características & 0,136 & 61,655 \\
\hline Dif. decorrente da política & 0,219 & \\
\hline Fonte: Amostra do Censo, 2000. Elaboração própria. & &
\end{tabular}

renças das características dos indivíduos e do efeito da política de atração de investimentos. Na tabela 7 são apresentados esses resultados.

Como pode ser observado na tabela 7 , cerca de $38,3 \%$ da diferença salarial podem ser atribuídos às características dos trabalhadores. Enquanto isso, a política de atração de empresas responde por $61,6 \%$ do diferencial de salários entre os trabalhadores que moram em municípios com empresas incentivadas e os residentes em municípios sem esse tipo de empresa.

\section{CONCLUSÃO}

A política industrial do Ceará é justificada, principalmente, pelo intento de se promover o desenvolvimento econômico do Estado. Nesse sentido, busca-se, mediante a atração de investimentos de empresas industriais, criar oportunidades de trabalho e promover o aumento da renda no Ceará.

Observando o atraso econômico, relativamente à RMF, dos municípios localizados fora dessa região, o Governo do Estado passou a ofertar maiores incentivos para as empresas que implantassem unidades produtivas naquele local.

Como conseqüência dessa política, algumas organizações industriais implantaram seus parques produtivos em diversos municípios do Estado. É interessante observar que, como visto anteriormente, os municípios onde estão instaladas essas empresas apresentam maior salário médio e maior percentual de trabalhadores com carteira assinada do que aqueles onde não existem empresas incentivadas; ou seja, pode-se considerar que há melhores condições de trabalho nos municípios com empresas atraídas do que naqueles que não possuem esse tipo de empresa.

Constatou-se, ainda, que as diferenças entre as características dos trabalhadores que residem nesses municípios explicam menos da metade do di- 
ferencial de salários entre esses dois grupos. Verifica-se que a adoção deste tipo de política contribui, com efeito, para o crescimento do prêmio salarial nos municípios com empresas incentivadas.

O maior prêmio salarial é um benefício óbvio da política de atração de investimentos; no entanto, deve-se alertar para o fato de essa política resultar, como efeito indesejado, no crescimento das disparidades entre os municípios cearenses. Assim, é oportuno sugerir que políticas compensatórias sejam adotadas para se tentar alcançar um desenvolvimento mais equilibrado entre as regiões do Estado do Ceará.

\section{NOTAS}

1. Nesse período, foi concluído o porto do Mucuripe, houve a expansão da rede distribuidora de energia elétrica para todo o Estado e a constituição do Distrito Industrial de Fortaleza, entre outras obras (Pontes, 2003).

2. Deve-se aqui frisar que, na década de 1990, várias obras de infra-estrutura (como o porto do Pecém, açude do Castanhão etc.) foram implementadas.

3. Para empresas situadas na RMF, esse empréstimo seria de $60 \%$ do ICMS a ser recolhido e de $75 \%$ para as localizadas fora da RMF. Os maiores incentivos concedidos para os estabelecimentos localizados além da RMF eram justificados pelo interesse de promover o desenvolvimento nas regiões mais atrasadas do Estado.

4. O prazo de duração dos incentivos passou a ser de 120 meses, para empresa localizada fora da RMF. O empréstimo poderia alcançar até $80 \%$ do ICMS arrecadado, e a correção seria dada por 30\% do IGP-M. A única alteração para empresas localizadas na RMF foi a aplicação da correção de 60\% do IGP-M.

5. O FDI constitui, sem dúvida, uma isenção fiscal para as empresas. Dessa forma, deve-se considerar que esse Fundo encontra-se no âmbito da "guerra fiscal". Esse conflito é travado entre os Estados brasileiros que oferecem incentivos fiscais para as empresas, normalmente industriais, que decidam se instalar em seus territórios. Como a intenção deste artigo é analisar apenas a política implementada pelo Governo do Estado do Ceará, não será aprofundado o debate sobre a "guerra fiscal".

6. Isso ocorreria no caso de um empresário fechar uma empresa, não atendida pelo FDI, para abrir outra, que, por ser nova, poderia ser enquadrada pelos incentivos concedidos pelo Governo do Estado.

7. Aqui não se considera a PNAD, que não discrimina o município de moradia do respondente.

8. Foram ainda excluídas as pessoas que não informaram o setor em que trabalhavam e que não disseram o salário total no trabalho principal. 
9. No período de janeiro de 1995 a dezembro de 1999, foram atraídas 274 empresas, que previam a geração de 59.070 postos de trabalho e o investimento de $\mathrm{R} \$ 4,25$ bilhões (a preços de janeiro de 2003). O número de municípios-sedes de empreendimentos atraídos foi de 56. Foram consideradas apenas as empresas que estavam em funcionamento em janeiro de 2003.

10. O setor agrícola é o grupo de referência, ou seja, os resultados obtidos têm como referência esse grupo.

11. O grupo de referência é o de trabalhador por conta própria.

12. Foi identificado, mediante o teste de White, que havia problemas de heterocedasticidade nos dados; optou-se, assim, pela matriz de covariância de White para corrigir o referido problema.

\section{REFERÊNCIAS BIBLIOGRÁFICAS}

ALMEIDA, M. B. de; SILVA, A. B. da. Estado do Ceará: desempenho econômico financeiro recente, 1990-1996. Revista Econômica do Nordeste, Fortaleza, v. 31, n. 4, p. 1.060-1.078, out./ dez., 2000.

KRUGMAN, P. Geography and Trade. Cambridge: The MIT Press, 1997. Chs. 1 e 2.

MARSHALL, A. Princípios de economia política. São Paulo: Abril Cultural, v. 1, 1982.

OAXACA, R. Male-female wage differentials in urban labor markets. International Economic Review, v. 14, n. 3, p. 693-709, 1973.

PONTES, P. A. Política industrial no Estado do Ceará: uma análise do FDI-Provin, 1979-2002. Fortaleza: UFC-Caen, 2003. Dissertação de Mestrado.

; VIANNA, P. J. R. Análise da Política de Incentivo ao Desenvolvimento Industrial do Estado do Ceará no Período 2001-2004. Nota Técnica, Fortaleza: Ipece, n. 12, 2005. 